Felix Stalder and Wolfgang Sützl:

\section{Ethics of Sharing}

Sharing has emerged as one of the core cultural values native to the networked environment. However, as Manuel Castells (2009, p. 126) put it: "In our society, the protocols of communication are not based on the sharing of culture but on the culture of sharing." This points to the fact that sharing, first and foremost, is a structural feature, a particular way of communicating and of organizing. It is often handled independently of what is being shared, or which effect these acts of sharing have in concrete situations. Thus, from a social or cultural point of view, sharing remains ambiguous, and its ethics needs to be examined in particular cases as well as across cases. Such examinations will position themselves beyond many of the popular debates, where sharing is often connected to a Utopian discourse, that may resonate deeply in Judeo-Christian thought, invoking images of community and justice that may or may not be justified.

The centrality of sharing within the network environment is connected to properties of digital information: firstly, that sharing means multiplying rather than dividing. Secondly, that digital information can be copied, distributed, accessed and transformed at an extremely low cost. Both run counter to the assumption of scarcity that underlies much economic thinking and through their mere existence tend to question the legitimacy of structures and institutions based on this assumption. A further consequence of these attributes of digital goods is that the differentiation between the producer and consumer is blurred through the emerging peer-to-peer paradigm and remix culture, where the old serves as the raw material for the new. Again, these are initially structural conditions that allow for new patterns to emerge. The next step, to which we hope to contribute with this special issue, is to examine sharing critically and develop an ethics around sharing practices that fosters the actual sharing of culture and the support of communities and allows a deeper understanding of the potentialities as well as the limitations of sharing practices on the level of the information society.

To do this, we need to be aware that sharing has many different meanings, some geared towards the social and others more towards the technical, and that we should not confuse the two (see
Andreas Wittel's contribution). We need to be critical of the contradiction between the culture of sharing amongst users and the commercial ambitions of many platforms on which this sharing takes place (Mayo Fuster, Marie-Louisa Frick/Andreas Oberprantacher), and, of course, the contradiction between the spread of a popular remix culture and the demands of intellectual property rights incompatible with it (Vito Campanelli). While sharing became a dominant theme in digital culture in the last few years, we should not forget that it is not related to particular new technological platforms and applications, but present also in earlier stages of the internet culture (Clemens Apprich). Keeping this in mind, it is productive, even if necessarily speculative, to enquire into sharing as a general paradigm that underlies social processes across different domains, informational as well as physical (Michel Bauwens, Alessandro Delfanti).

The Ethics of Sharing remains an open frontier of both contemporary social development and research in information ethics. At this point, everything is in flux, and what we need to do is trace early patterns and point to fields of contestation. We hope this special issue is a contribution to this collective process.

\section{References}

Castells, Manuel (2009). Communication Power. Oxford, Oxford University Press 